\title{
Low Frequency Electro-Acupuncture and Physical Exercise Induces Menstruation in a Young Woman with Amenorrhea Related to Polycystic Ovary Syndrome: A Case Report
}

\author{
Dongmei Huang ${ }^{1^{*}}$, Qing Wang ${ }^{1,2}$, Haoxu Dong ${ }^{2}$, Lina Zhang ${ }^{2}$ and Yanjuan Liu ${ }^{3^{*}}$ \\ ${ }^{1}$ Institute of Integrated Traditional Chinese and Western Medicine, Tongji hospital, Huazhong University of Science and Technology, China \\ ${ }^{2}$ Department of Obstetrics and Gynecology, First Affiliated Hospital, Heilongjiang University of Chinese Medicine, China \\ ${ }^{3}$ Department of Integrated Traditional Chinese and Western Medicine, Tongji hospital, Huazhong University of Science and Technology, China
}

*Corresponding author: Dongmei Huang, Institute of Integrated Traditional Chinese and Western Medicine, Tongji hospital, Huazhong University of Science and Technology, China, Tel: 8627 83663275; E-mail: hdmjcr@qq.com

Rec date: Jun 12, 2014; Acc date: July 25, 2014; Pub date: July 27, 2014

Copyright: (c) 2014 Huang D, et al. This is an open-access article distributed under the terms of the Creative Commons Attribution License, which permits unrestricted use, distribution, and reproduction in any medium, provided the original author and source are credited.

\begin{abstract}
Objectives: We report a successful case in a young woman with amenorrhea related to polycystic ovarian syndrome (PCOS) following low-frequency electro-acupuncture (EA) and physical exercise.

Subject: A 26 year old woman had secondary amenorrhea since 2002 and was diagnosed to have PCOS in 2007. She always took medroxyprogesterone acetate (MPA) for getting withdrawal bleeding every 3 months from 2002 to 2007. She had been treated with metformin, ethinylestradiol, cyproterone acetate tablets (Dyne-35) and Chinese medicine on an irregular basis from 2007 to April in 2012. When she attended our clinic, she had suffered from amenorrhea for 4 months as she stopped taking any medicine.
\end{abstract}

Interventions: The patient did regular physical exercise and received two courses of acupuncture treatment separated by an interval of 5 months. Each course of acupuncture treatment included 32 sessions of low-frequency EA.

Results: During the first course of EA treatment, she did not have any period returned. However, in the subsequent five months without any treatment, her periods returned four times. During the second EA treatment course, the patient had period for three times. Her abnormal high serum LH/FSH ratio reduced obviously and the morphology of polycystic ovaries was not found on pelvic scanning. During the following four months after the second EA treatment course, the patient had period for three times, and her sex hormone profile and ovarian morphology still kept normal.

Conclusion: This case illustrated that acupuncture and physical exercise can be an effective treatment for PCOS patients with ovulatory disorder.

\section{Introduction}

Polycystic ovary syndrome (PCOS) affects about 6-8\% of reproductive age women and is the most common reproductive endocrine disorder [1]. Women with PCOS are characterized by oligoovulation or anovulation, hyperandrogenism, polycystic ovary, inappropriate gonadotropin secretion (elevated level of circulating luteinizing hormone) and insulin resistance accompanying with compensatory hyperinsulinemia.

Acupuncture is a kind of non-drug therapy originated from traditional Chinese medicine. It is a safe treatment with few side effects [2]. Now it has been already widely used all over the world. Previous studies have shown that acupuncture can inhibit androgen secretion, regulate gonadotropin secretion and enhance ovulation and menstruation [3]. Here, we report a successful case in a young woman with amenorrhea related to PCOS following low-frequency electroacupuncture (EA) and physical exercise without using any other treatments including western medicine and Chinese herbs.

\section{Case History}

In August 2012, a 26 year old single woman attended the outpatient department of integrated traditional Chinese and western medicine in Tongji hospital for the treatment of amenorrhea related to PCOS. She complained of secondary amenorrhea since 2002 and had to take medroxyprogesterone acetate (MPA) every three months for withdrawal bleeding from 2002 to 2007. In November 2007, she took an ultrasonic examination showing that there were many small follicles liking honey comb in both ovaries. She told us she was diagnosed as PCOS at that time and had ever taken metformin, ethinylestradiol and cyproterone acetate tablets (Dyne-35) and Chinese medicine on an irregular basis from 2007 to April 2012. From April to August in 2012, she stopped taking any medicine for fear of potential side effects of the drugs and she did not have period during this period. Thus, she attended our clinic and resorted to complementary therapy other than medications.

On 26 January 2011, the patient underwent Oral Glucose Tolerance Test (OGTT) and Insulin Release Test (IRT), showing that Fasting 
Citation: Huang D, Wang Q, Dong X, Zhang L, Liu Y (2014) Low Frequency Electro-Acupuncture and Physical Exercise Induces Menstruation in a Young Woman with Amenorrhea Related to Polycystic Ovary Syndrome: A Case Report. Altern Integ Med 3: 166. doi: $10.4172 / 2327-5162.1000166$

Page 2 of 5

Plasma Glucose (FPG) and insulin (FIns), $1 \mathrm{~h}, 2 \mathrm{~h}$ and $3 \mathrm{~h}$ postprandial plasma glucose and insulin were all normal. But the insulin secretion peak was postponed to $3 \mathrm{~h}$ postprandial.

On 10 March 2012 (the third day of menstruation, D3), serum levels of sex hormones were examined as the following: Luteinizing Hormone (LH) level was $18.78 \mathrm{IU} / \mathrm{L}$, follicle-stimulating hormone (FSH) level was $4.67 \mathrm{IU} / \mathrm{L}$, prolectin (PRL) level was $10.59 \mu \mathrm{g} / \mathrm{L}$, progesterone (P) level was $1.89 \mathrm{nmol} / \mathrm{L}$, Estradiol (E2) level was 156.6 $\mathrm{pmol} / \mathrm{L}$ and Testosterone (T) level was $2.02 \mathrm{nmol} / \mathrm{L}$.

On 3 August 2012, the patient undertook an ultrasonic examination, showing that there were over 12 follicles with diameter $<10 \mathrm{~mm}$ in both ovaries.

Before our intervention, the patient is $155 \mathrm{~cm}$ high and $60 \mathrm{~kg}$ weight. Her body mass index (BMI) is 25 .

\section{Materials and Methods}

\section{Life style intervention}

The patient was informed of benefits of regular physical exercise for PCOS [4]. Since August 2012 until now, she has kept on physical exercise including jogging, cycling and kick boxing regularly, 4-5 times a week and each time lasting for about 2 hours. Physical exercise was self-monitored by counting her pulse rate to ensure a heart rate of 120 beats/min.

\section{Acupuncture treatment}

The patient received two courses of low-frequency EA treatment with a maximum of 32 treatment sessions in each course. The lowfrequency EA treatment was performed twice a week and each treatment session lasting for 30 minutes was separated by an interval of 2-4 days. EA treatment was stopped during menstruation. The acupuncture was conducted by two qualified acupuncturists with over 3 years of clinical experience.

Acupuncture protocol was as same as that used in reference [5]. Two sets of acupoints were used alternatively. The first set consisted of conception vessel (CV) 3, CV 6, governor vessel (GV) 20 and bilateral stomach (ST) 29, spleen (SP) 6, SP 9, large intestine (LI) 4 (Figure. 1). Disposable, single-use, sterilized needles (Size: $0.25 \times 40 \mathrm{~mm}$ and 0.30 $\times 40 / 50 \mathrm{~mm}$; Lot: 251226; Wuxi Jiajian Medical Instrument, Wuxi, China) made of stainless steel were inserted into a depth of $15-35 \mathrm{~mm}$ and stimulated manually to evoke needle sensation (de qi). CV 3, CV 6, ST 29, SP 6 and SP 9 were thereafter connected to electrical stimulator (Export Abteilung, Schwa-Medico GmbH, Wetzlarer Str. 41-43; 35630 Ehringshausen) and stimulated with low-frequency EA of $2 \mathrm{~Hz}, 0.3 \mathrm{~ms}$ pulse. The length and intensity were adjusted to produce local muscle contractions without pain or discomfort. Needles which were not connected to the electrical stimulator were manually stimulated to evoke needle sensation every $10 \mathrm{~min}$, in total 4 times. The second set of acupoints consists of ST 25 and ST 29 bilaterally (electrical stimulation), SP 6 and liver (LR) 3 bilaterally (electrical stimulation), CV 3 and CV 6 (manual stimulation), pericardium (PC) 6 bilaterally and GV 20 (both manual stimulation) (Figure 2). The method of electrical stimulation is the same as the first set.

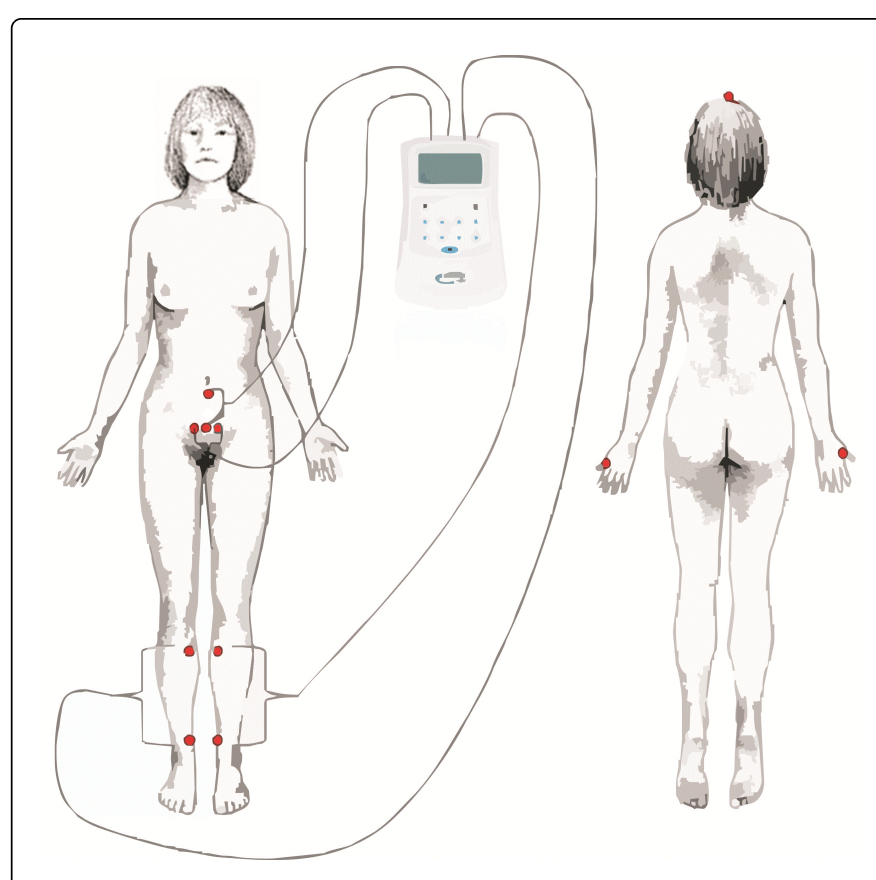

Figure 1: Location of the first set of acupuncture points

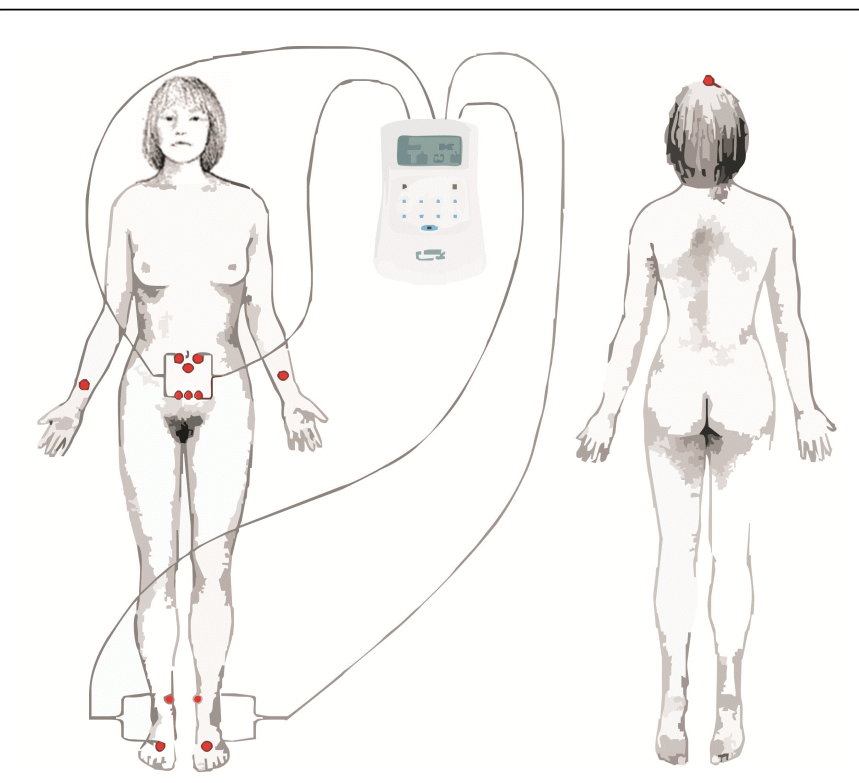

Figure 2: Location of the second set of acupuncture points

From August 2012 to January 2013, the patient received the first course of EA treatment which started shortly after a withdrawal bleeding following progestin? Because of the return of periods after the first course of EA treatment, she asked for another course of EA treatment. Thus, from July to December 2013, the patient received the second course of EA treatment and the protocol of EA was the same as the first course. 
Citation: Huang D, Wang Q, Dong X, Zhang L, Liu Y (2014) Low Frequency Electro-Acupuncture and Physical Exercise Induces Menstruation in a Young Woman with Amenorrhea Related to Polycystic Ovary Syndrome: A Case Report. Altern Integ Med 3: 166. doi: $10.4172 / 2327-5162.1000166$

Page 3 of 5

\section{Results}

\section{Menstruation}

During the first course of EA treatment (32 acupuncture sessions), the patient did not have any period returned. However, after the first course of EA treatment was finished, from January to June 2013, the patient had periods for four times respectively on 7 February, 27 March, 26 May and 26 June of 2013. During this period, the patient just went on jogging, cycling and kick boxing as before without any other treatments.

During the second course of EA treatment, the patient got periods for 3 times respectively on 11 September, 19 October and 23 November of 2013.

After she finished two courses of acupuncture in December 2013, the patient got periods for 3 times respectively on 31 Juanuary, 14 March and 20 April, of 2014.

\section{Ultrasonography examination}

On 4 June, 2013 (the tenth day of menstruation, D10), the patient underwent a color Doppler ultrasonography(CDU) examination, showing that there were 5-6 follicles in the right ovary with a $19 \times 14$ $\mathrm{mm}$ dominant follicle and 6-7 follicles in the left ovary.

On 7 November, 2013 (the $20^{\text {th }}$ day of menstruation, D20), the patient received ultrasonic examination, showing that there were about 10 follicles in both ovaries with a $18 \times 17 \mathrm{~mm}$ dominant follicle in the right ovary.
On 3 April, 2014 (the twenty-first day of menstruation, D21), ultrasonic examination showed that there was a $1.6 \times 1.5 \mathrm{~cm}$ dominant follicle in the right ovary.

\section{Serum levels of sex hormones}

On 28 June, 2013 (the third day of menstruation, D3), serum levels of sex hormones of the patient was observed showing $\mathrm{LH}$ level 0.34 IU/L, FSH level $1.18 \mathrm{IU} / \mathrm{L}$, PRL level $7.35 \mu \mathrm{g} / \mathrm{L}$, P level $2.45 \mathrm{nmol} / \mathrm{L}$ $(0.77 \mathrm{ng} / \mathrm{ml})$, E2 level $77.1 \mathrm{pmol} / \mathrm{L}(21.00 \mathrm{pg} / \mathrm{ml})$ and $\mathrm{T}$ level 0.60 $\mathrm{nmol} / \mathrm{L}(0.19 \mathrm{ng} / \mathrm{ml})$.

On 13 September, 2013 (the third day of menstruation, D3), serum levels of LH, FSH and T were $0.11 \mathrm{IU} / \mathrm{L}, 0.87 \mathrm{IU} / \mathrm{L}$ and $0.96 \mathrm{nmol} / \mathrm{L}$, respectively.

On 16 March, 2014 (the third day of menstruation, D3), serum levels of sex hormones were detected as: LH level $4.73 \mathrm{IU} / \mathrm{L}$, FSH level $3.41 \mathrm{IU} / \mathrm{L}$, E2 level $84.4 \mathrm{pmol} / \mathrm{L}(23.00 \mathrm{pg} / \mathrm{ml})$ and T level $0.98 \mathrm{nmol} / \mathrm{L}$ $(0.31 \mathrm{ng} / \mathrm{ml})$.

\section{OGTT and IRT}

On 5 November, 2013, the patient took an OGTT and IRT once again. The results showed that $3 \mathrm{~h}$ postprandial plasma glucose (3hPG) was lower than normal and $1 \mathrm{~h}$ postprandial insulin (1hIns) was higher than normal, whereas the other criteria were all normal.

The weight of the patient was always about $60 \mathrm{~kg}$ without obvious change during the total intervention (EA and/or physical exercise). All the results are showed in Table 1.

\begin{tabular}{|c|c|c|c|c|c|}
\hline Period & $\begin{array}{l}4 \quad \text { months before } \\
\text { acupuncture treatment }\end{array}$ & $\begin{array}{l}\text { First course of } \\
\text { acupuncture treatment }\end{array}$ & $\begin{array}{l}6 \text { months after the first } \\
\text { course of acupuncture } \\
\text { treatment }\end{array}$ & $\begin{array}{l}\text { Second course of } \\
\text { acupuncture treatment }\end{array}$ & The following 4 months \\
\hline Time & $\begin{array}{l}\text { from April to August, } \\
2012\end{array}$ & $\begin{array}{l}\text { from August, } 2012 \text { to } \\
\text { January, 2013 }\end{array}$ & from January to July, 2013 & $\begin{array}{l}\text { from July to December, } \\
2013\end{array}$ & $\begin{array}{l}\text { From December, } 2013 \text { to } \\
\text { April, } 2014\end{array}$ \\
\hline Intervention & no intervention & $\begin{array}{l}\text { EA plus physical } \\
\text { exercise }\end{array}$ & physical exercise & EA plus physical exercise & physical exercise \\
\hline BMI & 25 & 25 & 25 & 25 & 25 \\
\hline Menstruation & zero & zero & 4 times & 3 times & 3 times \\
\hline Ultrasonic examination & $\begin{array}{l}\text { 2012.08.03: } \\
>12 \text { follicles in both } \\
\text { ovaries; without follicle } \\
\text { larger than } 10 \times 10 \mathrm{~mm}\end{array}$ & no & $\begin{array}{l}\text { 2013.06.04(D10): } \\
5-6 \text { follicles in the right } \\
\text { ovary with a } 19 \times 14 \quad \mathrm{~mm} \\
\text { dominant follicle; } 6-7 \\
\text { follicles in the left ovary }\end{array}$ & $\begin{array}{l}\text { 2013.11.07(D20): } \\
\text { About 10 follicles in both } \\
\text { ovaries; with a } 18 \times 17 \mathrm{~mm} \\
\text { dominant follicle }\end{array}$ & $\begin{array}{l}2014.4 .3 \text { (D21): } \\
\text { there was a 1.6×1.5 cm } \\
\text { dominant follicle in the } \\
\text { right ovary }\end{array}$ \\
\hline $\begin{array}{l}\text { Serum levels of sex } \\
\text { hormones }\end{array}$ & $\begin{array}{l}\text { 2012.03.10(D3): } \\
\text { LH: } 18.78 \mathrm{IU} / \mathrm{L} \\
\text { FSH: } 4.67 \mathrm{IU} / \mathrm{L} \\
\text { PRL: } 10.59 \mathrm{\mu g} / \mathrm{L} \\
\text { PROG: } 1.89 \mathrm{nmol} / \mathrm{L} \\
\text { E2: } 156.6 \mathrm{pmol} / \mathrm{L} \\
\text { T: } 2.02 \mathrm{nmol} / \mathrm{L}\end{array}$ & no & $\begin{array}{l}2013.6 .28(\mathrm{D} 3): \\
\text { LH: } 0.34 \mathrm{IU} / \mathrm{L} \\
\text { FSH: } 1.18 \mathrm{IU} / \mathrm{L} \\
\text { PRL: } 7.35 \mu \mathrm{g} / \mathrm{L} \\
\text { PROG: } 2.45 \mathrm{nmol} / \mathrm{L} \\
\text { E2: } 77.1 \mathrm{pmol} / \mathrm{L} \\
\text { T: } 0.60 \mathrm{nmol} / \mathrm{L}\end{array}$ & $\begin{array}{l}\text { 2013.9.13(D3): } \\
\text { LH: } 0.11 \mathrm{IU} / \mathrm{L} \\
\text { FSH: } 0.87 \mathrm{IU} / \mathrm{L} \\
\mathrm{T}: 0.96 \mathrm{nmol} / \mathrm{L}\end{array}$ & $\begin{array}{l}2014.3 .16 \text { (D3): } \\
\text { LH: } 4.73 \mathrm{IU} / \mathrm{L} \\
\text { FSH: } 3.41 \mathrm{IU} / \mathrm{L} \\
\text { E2: } 84.4 \mathrm{pmol} / \mathrm{L} \\
\text { T: } 0.98 \mathrm{nmol} / \mathrm{L}\end{array}$ \\
\hline OGTT & $\begin{array}{l}2011.01 .26: \\
\text { FPG: } 4.91 \mathrm{mmlo} / \mathrm{L} \\
\text { 1hPG: } 4.99 \mathrm{mmlo} / \mathrm{L} \\
\text { 2hPG: } 6.22 \mathrm{mmlo} / \mathrm{L}\end{array}$ & no & no & $\begin{array}{l}\text { 2013.11.05: } \\
\text { FPG: } 4.78 \mathrm{mmlo} / \mathrm{L} \\
\text { 1hPG: } 7.14 \mathrm{mmlo} / \mathrm{L} \\
\text { 2hPG: } 6.35 \mathrm{mmlo} / \mathrm{L}\end{array}$ & no \\
\hline
\end{tabular}


Citation: Huang D, Wang Q, Dong X, Zhang L, Liu Y (2014) Low Frequency Electro-Acupuncture and Physical Exercise Induces Menstruation in a Young Woman with Amenorrhea Related to Polycystic Ovary Syndrome: A Case Report. Altern Integ Med 3: 166. doi: $10.4172 / 2327-5162.1000166$

Page 4 of 5

\begin{tabular}{|c|c|c|c|c|c|}
\hline & 3hPG: $3.63 \mathrm{mmlo} / \mathrm{L}$ & & & 3hPG: $2.60 \mathrm{mmlo} / \mathrm{L}$ & \\
\hline IRT & $\begin{array}{l}2011.01 .26 \text { : } \\
\text { FIns: } 9.40 \text { ulU/L } \\
\text { 1hlns: } 21.50 \text { ulU/L } \\
\text { 2hlns:36.20 ulU/L } \\
\text { 3hlns: } 5.90 \text { ulU/L }\end{array}$ & no & no & $\begin{array}{l}\text { 2013.11.05: } \\
\text { Flns: } 9.67 \text { ulU/L } \\
\text { 1hlns: } 80.51 \text { ulU/L } \\
\text { 2hlns:44.24 ulU/L } \\
\text { 3hlns: } 5.21 \text { ulU/L }\end{array}$ & no \\
\hline
\end{tabular}

Table 1: Treatment and progress, BMI-Body Mass Index; LH-Luteinizing Hormone; FSH- Follicle-Stimulating Hormone. PRL- Prolactin; PProgesterone; E2-Estradiol; T-Testosterone

\section{Discussion}

PCOS is the most common endocrinopathy in women of reproductive age. Women with PCOS may complain of various clinical manifestations including oligomenorrhea or amenorrhea, hirsutism, acne, and infertility. Oligomenorrhea or amenorrhea is usually the biggest problem disturbing young PCOS girls who have no immediate fertility wish and also usually the primary reason for them to see a doctor for the first time. Those methods such as clomiphene citrate, exogenous gonadotropin therapy, and laparoscopic ovarian drilling which are commonly used to induce ovulation [6] are not suitable for this part of PCOS patients.

In this case, before the patient received the intervention of physical exercise and acupuncture treatment, she had suffered from secondary amenorrhea for about 10 years and just took progestin or Dyne-35 for withdrawal bleeding. Her serum $\mathrm{T}$ level was normal and she had no acne and hirsutism. However, her LH/FSH ratio was 4.02, much higher than normal and there were over 12 small follicles with diameter $<10 \mathrm{~mm}$ in both ovaries. According to the Rotterdam's criteria [7], the patient conformed to the diagnosis of PCOS.

It is uncertain why she did not have periods returned during the first course of acupuncture treatment. But after she finished the first course of acupuncture treatment, she had periods for 4 times in the following 6 months without any medication and further 3 times during the second course of acupuncture treatment. We deduced that maybe acupuncture produce effect only when acupuncture treatment achieves a certain quantity, and it has a post-treatment effect for a long time, which has been observed in animal experiments $[8,9]$. In $5 \alpha-$ dihydrotestosterone-induced PCOS rats who received $2 \mathrm{~Hz}$ EA five times per week for $4-5$ weeks, $88 \%$ of them had oestrous cycle change only during the last 2 weeks of EA treatment [8].

At the end of interval between two courses of acupuncture treatment, her LH level on the third day of menstruation decreased markedly from $18.78 \mathrm{IU} / \mathrm{L}$ before treatment to $0.34 \mathrm{IU} / \mathrm{L}$, whereas her FSH level also decreased from 4.67 IU/L to $1.18 \mathrm{IU} / \mathrm{L}$ and her T level decreased from $2.02 \mathrm{nmol} / \mathrm{L}$ to $0.60 \mathrm{nmol} / \mathrm{L}$. During the second course of acupuncture treatment, her LH level continued to decrease from $0.34 \mathrm{IU} / \mathrm{L}$ to $0.11 \mathrm{IU} / \mathrm{L}$ and FSH level decreased from $1.18 \mathrm{IU} / \mathrm{L}$ to 0.87 $\mathrm{IU} / \mathrm{L}$, whereas $\mathrm{T}$ level increased from $0.60 \mathrm{nmol} / \mathrm{L}$ to $0.96 \mathrm{nmol} / \mathrm{L}$. It seemed that acupuncture plus physical exercise inhibited the secretion of LH, FSH and T and this effect became much more obvious on $\mathrm{LH}$ and FSH with the prolongation of intervention.

The influence of acupuncture on sex hormones also has been found by other investigators. Johansson et al. [10] found that acupuncture decreased testosterone, free testosterone, estradiol, dehydroepiandrosterone, dehydroepiandrosterone sulfate and androstenedione accompanied by a higher ovulation frequency, but with no effect on LH secretion. Pastore et al. [11] had a different conclusion. They observed that acupuncture decreased LH/FSH ratio from $1.9 \pm 1.4$ at baseline to $1.4 \pm 1.4(\mathrm{P}=0.039)$ after 12 sessions of acupuncture and further to $1.3 \pm 0.7(\mathrm{P}=0.001)$ post three-month follow-up, also lowered free testosterone and fasting insulin, and improved ovulation even they did not find a difference between true and sham acupuncture. Acupuncture may alter the release of GnRH and CRH through influencing hypothalamic $\beta$-endorphin secretion, and then further produce an effect on LH and FSH secretion [12]. Furthermore, excessive physical exercise can inhibit LH and FSH secretion [13]. For this patient, EA combined with physical exercise had a very obviously inhibitory effect on LH, FSH and T secretion, especially on LH and FSH secretion.

Because the levels of LH and FSH decreased too much and had already been lower than normal, we ever advised the patient to stop EA treatment. But the patient insisted on finishing the second course of acupuncture treatment. We also advised the patient to reduce the strength and duration of exercise and monitor the serum levels of sex hormones in six months. Her serum levels of LH and FSH showed normal on 16 March, 2014 when she had already stopped EA treatment and reduced the strength and duration of the exercise for nearly three months. We has not yet known the accurate reason why her serum levels of LH and FSH recover to normal, which may be related to both the cease of EA and the reduction of physical exercise. Therefore, we should monitor the serum levels of sex hormones and then regulate the frequency of EA treatment and the intensity of physical exercise according to the change of sex hormone levels in the treatment of PCOS.

Before our intervention, the ovaries of the patient showed as typical polycystic change with over 12 small follicles in both ovaries. However, the patient took ultrasonic examination for three times respectively at six months after the first course of acupuncture treatment, during the second course of acupuncture treatment and five months after the second course of acupuncture treatment, which all found a dominant follicle $(19 \times 14 \mathrm{~mm}, 18 \times 17 \mathrm{~mm}$ and $16 \times 15 \mathrm{~mm}$, respectively) and no more than 12 follicles in both ovaries. Acupuncture combined with physical exercise was effective in inducing the production of dominant follicle and ovulation. It has been observed that EA and exercise improved ovarian morphology in PCOS rats, maybe through modulation of sympathetic outflow to the ovaries [9].

About $42 \%$ of PCOS patients have insulin-resistance, and $48 \%$ have hyperandrogenism. Insulin-resistance is commonly associated with hyperinsulinemia, and the latter enhances androgen production by theca cells and leads to hyperandrogenism [14]. Therefore, insulinsensitizing drugs are used to inhibit or limit testosterone production, 
Citation: Huang D, Wang Q, Dong X, Zhang L, Liu Y (2014) Low Frequency Electro-Acupuncture and Physical Exercise Induces Menstruation in a Young Woman with Amenorrhea Related to Polycystic Ovary Syndrome: A Case Report. Altern Integ Med 3: 166. doi: $10.4172 / 2327-5162.1000166$

Page 5 of 5

and improve spontaneous ovulation and regular menstrual cycles in PCOS patients. Lifestyle modification including physical exercise can reduce body weight and improve insulin resistance, which are beneficial to PCOS [15]. Before the patient came to us, she had normal glucose tolerance and insulin sensitivity. During the total intervention, her weight and BMI did not change at all. Except that 1hPG and 1hIns after 15 months of intervention were nearly 1.5 and 4 times those before intervention respectively, there was no obvious change in FPG, FIns, 2hPG, 2hIns, $3 \mathrm{hPG}$ and $3 \mathrm{hIns}$ after intervention. Therefore, for this patient, it seemed that physical exercise did not produce effect on PCOS through improving insulin resistance or reducing hyperinsulinemia. However, we cannot deny the beneficial influence of physical exercise on PCOS [16], which may through regulating the secretion of LH, FSH or Tt.

In conclusion, after the intervention of physical exercise and two courses of acupuncture treatment, the patient's menstruation improved markedly, her abnormal high LH/FSH ratio dropped down greatly and the morphology of the polycystic ovaries was not found on pelvic scanning. Our result is similar to aother study [17] which showing that either Low-frequency EA or physical exercise improved hyperandrogenism and menstrual frequency more effectively than no intervention in women with PCOS or Low-frequency EA was superior to physical exercise. In this case, we combined EA with physical exercise to treat PCOS, which showed much more inhibitory effects on $\mathrm{LH}, \mathrm{FSH}$ and $\mathrm{T}$ secretion. Now our research team is doing a randomized controlled clinical trial about the effect of EA on PCOS (United States National Institutes of Health Clinical Trials Registry : NCT 01812161). It will disclose the effectiveness of acupuncture as a treatment for PCOS women. We think it necessary to commit a clinical trial to investigate the role of acupuncture combined with physical exercise, and to compare the effect of both acupuncture and physical exercise with either one. It will be an excitement If we can find a kind of non-medical treatment for oligo-/amenorrhea, hyperandrogenism and ovulation dysfunction in PCOS.

\section{Conclusions}

This case illustrated that acupuncture and physical exercise can achieve return of menstruation in PCOS patients with amenorrhea. Acupuncture integrated with physical exercise may be a good substitute for medication in the treatment of PCOS.

\section{Acknowledgements}

All authors are very grateful to Dr. Ernest Hung Yu Ng (department of obstetrics \& gynecology, university of Hong Kong, Hong Kong) for proofreading this manuscript.

\section{References}

1. Azziz R, Woods KS, Reyna R, Key TJ, Knochenhauer ES, et al (2004) The prevalence and features of the polycystic ovary syndrome in an unselected population. Journal of Clinical Endocrinology and Metabolism 89: 2745-2749.

2. Witt CM, Pach D, Brinkhaus B, Wruck K, Tag B, et al (2009) "Safety of acupuncture: results of a prospective observational study with 229,230 patients and introduction of a medical information and consent form." Forschende Komplementärmedizin 16: 91-97.

3. Johansson J1, Stener-Victorin E (2013) Polycystic ovary syndrome: effect and mechanisms of acupuncture for ovulation induction. Evidence-Based Complementary and Alternative Medicine Epub.

4. Stener-Victorin E, Jedel E, Janson PO, Sverrisdottir YB (2009) Lowfrequency electro-acupuncture and physical exercise decrease high muscle sympathetic nerve activity in polycystic ovary syndrome. American Journal of Physiology Regulatory, Integrative and Comparative Physiology 297: 387-395.

5. Kuang $\mathrm{H}, \mathrm{Li} \mathrm{Y}, \mathrm{Wu} \mathrm{X}, \mathrm{Hou} \mathrm{L}, \mathrm{Wu} \mathrm{T}$, et al (2013) Acupuncture and clomiphene citrate for live birth in polycystic ovary syndrome: study design of a randomized controlled trial. Evid Based Complement Alternat Med.

6. The Thessaloniki ESHRE/ASRM-Sponsored PCOS Consensus Workshop Group: Consensus on infertility treatment related to polycystic ovary syndrome (2008) Hum Reprod $23: 462-477$.

7. Rotterdam ESHRE/ASRM-Sponsored PCOS consensus workshop group (2004) Revised 2003 consensus on diagnostic criteria and long-term health risks related to polycystic ovary syndrome (PCOS). Hum Reprod 19: 41-47.

8. Feng Y, Johansson J, Shao R, Manneras-Holm L, Billig H, et al. (2012) Electrical and manual acupuncture stimulation affects estrouscy clicity and neuroendocrine function in a DHT-induced rat polycystic ovary syndrome model. Exp Physio 197: 651-662.

9. Manneras L, Cajander S, Lonn M, Stener-Victorin E (2009) Acupuncture and exercise restore adipose tissue expression of sympathetic markers and improve ovarian morphology in rats with dihydrotestosteroneinduced PCOS. Am J Physiol Regul Integr Comp Physio 1296: 1124-1131.

10. Johansson J, Redman L, Veldhuis PP, Sazonova A, Labrie F, et al (2013) Acupuncture for ovulation induction in polycystic ovary syndrome: a randomized controlled trial. Am J Physiol Endocrinol Metab 304: E934-943.

11. Pastore LM, Williams CD, Jenkins J, Patrie JT (2011) True and sham acupuncture produced similar frequency of ovulation and improved LH to FSH ratios in women with polycystic ovary syndrome. J Clin Endocrinol Metab 96: 3143-3150.

12. Johansson J, Stener-Victorin E (2013) Polycystic ovary syndrome: effect and mechanisms of acupuncture for ovulation induction. Evid Based Complement Alternat Med.

13. Orio F, Muscogiuri G, Ascione A, Marciano F, Volpe A, et al. (2013) Effects of physical exercise on the female reproductive system. Minerva Endocrinologica 38: 305-319.

14. Abbott DH, Bacha F (2013) Ontogeny of polycystic ovary syndrome and insulin resistance in utero and early childhood. Fertil Steril 100: 2-11.

15. Haqq L, McFarlane J, Dieberg G, Smart N (2014) Effect of lifestyle intervention on the reproductive endocrine profile in women with polycystic ovarian syndrome: a systematic review and meta-analysis. Endocr Connect 3: 36-46.

16. Domecq JP, Prutsky G, Mullan RJ, Hazem A, Sundaresh V, et al (2013) Lifestyle modification programs in polycystic ovary syndrome: systematic review and meta-analysis. J Clin Endocrinol Metab 98: 4655-4663.

17. Jedel E, Labrie F, Odén A, Holm G, Nilsson L, et al (2011) Impact of electro-acupuncture and physical exercise on hyperandrogenism and oligo/amenorrhea in women with polycystic ovary syndrome: a randomized controlled trial. Am J Physiol Endocrinol Metab 300: E37-45. 